\title{
Problem Solving Case Studies in Analytical and Applied Chemistry
}

\begin{abstract}
Summary
We have produced six problem solving case studies which have been designed in order to teach analytical and applied chemistry within a 'real' life context by developing problem solving and professional skills. The case studies use the contexts of forensic science, pharmaceuticals, environmental science, and industrial chemistry. They present students with extended problems that are set in a 'real' context with incomplete or excessive data, and require independent learning, evaluation of data and information and, in some cases, do not lead to a single 'correct' answer. By tackling these cases, students are able to see the relevance of analytical chemistry and so approach the activities with enthusiasm and interest. In order to successfully tackle a case study, students must develop a range of professional skills such as communication, team work, project management, etc.
\end{abstract}

Subject area: Chemistry

\section{Description}

Each case study uses a problem based learning approach in order to develop subject specific knowledge and a range of professional skills. Each case study extends over several class room sessions (typically 4-6) and requires students to carry out independent study (typically 6-12). Although we identify a level at which the case studies may most usefully be used, this does depend on the background of the students, the level of support provided by the tutor and the intended learning outcomes of the module. The case studies are paper based and are provided with a tutors guide and student handouts. The tutor's guides include an overview of the case, tips for running the activity successfully, an assessment guide and typical sessions plans. A summary of each case study is given here.

\section{New Drugs for Old}

This is a problem-based case study concerned with the isolation, identification and synthesis of a pharmaceutical. The students consider the short-term experiments that would be required to isolate and identify the active ingredient in some dried leaves from Malaysia. They then propose the longer-term experiments that would be required to bring the drug to the market place.

The students interpret the NMR, MS and FT-IR spectra to identify a series of isolated components. They then cost the synthesis of the active ingredient from cheap substrates, but realise that this approach is likely to be financially less viable than purchasing it directly.

$\begin{array}{ll}\text { Suggested level } & 1^{\text {st }} \text { or } 2^{\text {nd }} \text { level } \\ \text { Context } & \text { Analytical and pharmaceutical chemistry } \\ \text { Contact time } & 4 \text { hours } \\ \text { Independent study } & 10 \text { hours } \\ \text { Possible assessment } & \text { One page project plan, written report, oral presentation. }\end{array}$




\section{The Titan Project}

This case study concerns the siting of a titanium dioxide plant and evaluation of analytical methods. Students adopt the role of the existing management team of a titanium dioxide plant and are asked to make recommendations on the future of the site to the board. This encourages them to consider industrial chemistry in a broad context of the associated safety, environmental, economic and social issues. They compare the sulphate and chloride processes for $\mathrm{TiO}_{2}$ production, and finally propose a five-year strategy for the site. The students then consider setting up an Environmental Monitoring Laboratory for the chloride process and must select and evaluate a method of analysis for chloride ions in effluent.

$\begin{array}{ll}\text { Suggested level } & 1^{\text {st }} \text { or } 2^{\text {nd }} \text { level } \\ \text { Context } & \text { Analytical chemistry, Industrial chemistry } \\ \text { Contact time } & 4 \text { hours } \\ \text { Independent study } & 10 \text { hours } \\ \text { Assessment } & \text { Oral presentations, review of methods, individual exercises }\end{array}$

\section{A Dip in the Dribble}

This case study is set within the context of an investigation of the environmental impact of river pollution. A fire in a warehouse has resulted in diquat dibromide and p-octylphenol entering the River Dribble. Students determine the cause of the incident and review the probable environmental impact of the chemicals released. Then they consider possible methods of analysis and, finally, commission a monitoring programme for diquat dibromide and $p$-octylphenol in the river by selecting a contract analysis company from the information supplied.

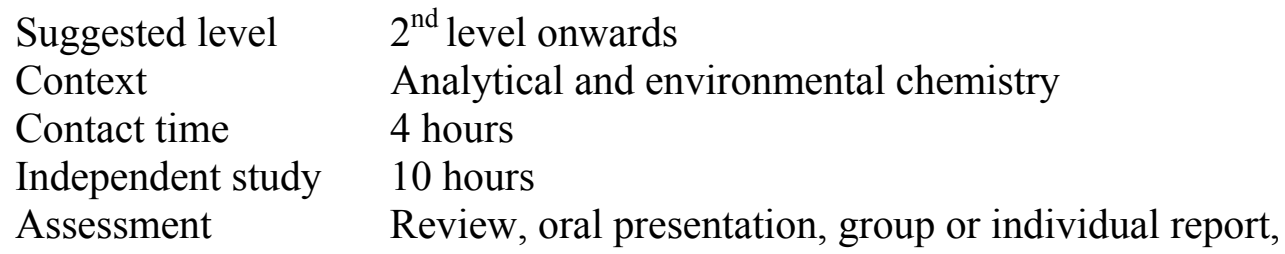

\section{The Pale Horse}

This case study uses the context of a forensic investigation of a suspicious death. It operates by supplying information in the form of reports from various official agencies (police, pathologist and forensic laboratory). The students request analysis of the various types of evidence collected in order to determine the cause of death, mode of administration of poison and suggest the identity of the possible perpetrators.

Suggested level $\quad 2^{\text {nd }}$ level onwards

Context Analytical chemistry and forensic science

Contact time 5 hours

Independent study 10 hours

Assessment Case summary, oral presentations, group or individual report

\section{Tales of the Riverbank}

This case study is set within the context of the investigation of environmental problems along a river system. Students assume the role of the investigation team following a complaint about a reduction in the number and size of fish caught along 
the river. By considering both temporal and spatial factors, the students identify an array of possible causes. As further data and information is made available, the groups are required to consider environmental issues, pollution, sampling, analytical techniques, water quality, data analysis / interpretation, toxicity, and remediation.

Suggested level $\quad 2^{\text {nd }}$ level onwards

Context Analytical chemistry and environmental chemistry

Contact time 5-6 hours

Independent study 12 hours

Assessment Oral presentations, group report

\section{Launch a Lab}

This uses the context of a small contract analysis company that is tendering for a large new contract for the analysis of organic pollutants in ground water. The students act as part of the management team whose task is to ensure that the company can deliver a high quality service with a suitable profit margin if they secure the contract. The must consider issues such as validation, accreditation, marketing, buying equipment and lab design. As new staff are required to deliver the expanded service, students advertise a post and interview candidates. They also apply for a job advertised by other students and are interviewed for the post.

Suggested level $\quad 2^{\text {nd }}$ level onwards

Context Analytical chemistry and professional skills

Contact time 5 hours

Independent study 10 hours

Assessment Oral presentation, poster, $\mathrm{CV}$, interviews and interviewing

\section{Type of activity}

Problem solving case study. Paper based. Students work in small groups throughout.

\section{Content covered}
A Dip in the Dribble
Analytical, environmental and industrial chemistry
Launch-a-Lab
New Drugs for Old Industrial chemistry and advanced professional skills
Tales of the Riverbank
The Pale Horse
The Titan Project
Pharmaceutical and analytical chemistry
Analytical chemistry and environmental science
Analytical chemistry and forensic science
Industrial and analytical chemistry

\section{Application}

The case studies are designed to be flexible. Consequently, they may be used as a complete package or individual activities may be used within different contexts. They have been successfully used in modules on analytical chemistry, forensic science, environmental chemistry, industrial chemistry and professional skills.

\section{Further comments}

This project was funded by the Royal Society of Chemistry Analytical Chemistry Trust Fund 
New Directions in the Teaching of Physical Sciences

\section{Author(s)}

Simon Belt, School of Environmental Science, University of Plymouth

Tina Overton, Department of Chemistry, University of Hull

Stephen Summerfield, formerly University of Hull

\section{Contact details}

For a copy of the case studies contact:

Dr Tina Overton, Department of Chemistry, University of Hull, t.l.overton@hull.ac.uk

Dr Simon Belt, School of Environmental Sciences, University of Plymouth sbelt@plymouth.ac.uk 